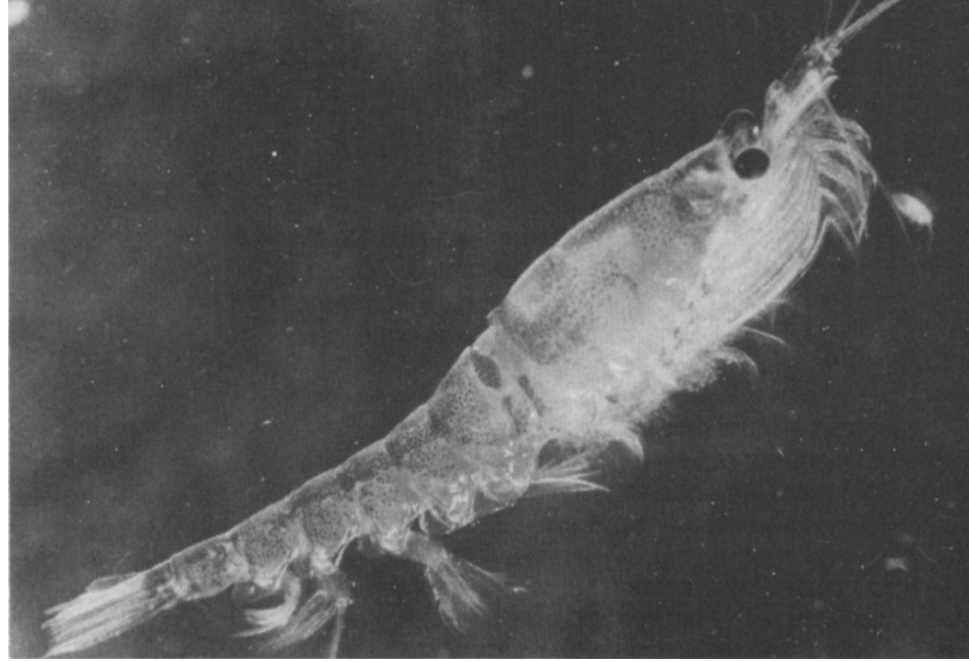

\title{
The Krill Problem in Antarctica
}

\section{W. Nige/ Bonner}

Krill fishing in the Southern Ocean has raised in acute form the question of wildlife conservation in Antarctica: what will be the effect on the ecosystem? how much krill can be taken? who can take part? what regulations are needed? The author, a scientist of the British Antarctic Survey, considers the answers in the light of the Antarctic Treaty of 1959 and the Canberra Convention on the Conservation of Antarctic Marine Living Resources of 1980 , and looks at some criticisms of the latter put forward in a recently published book. He suggests that the Convention, while not ideal, is to be welcomed because it provides a framework for conservation and rational exploitation that can be made to work - if the nations that signed it are determined to make it do so.

The Antarctic represents a huge part of the earth's surface. The land mass (which is almost totally covered by an ice sheet with an average thickness of over a mile) is larger in area than the whole of Europe, or the USA and Mexico combined, or India and China taken together. Surrounding this is a sea, the Southern Ocean, separated from the other world oceans by the Antarctic Convergence, where the cold northward-flowing Antarctic surface water dips sharply beneath the warmer water to the north. The Southern Ocean covers approximately 35 million sq $\mathrm{km}$ or about one tenth of the world's ocean surface. Parts of this vast ocean are highly productive, and overall it supports huge populations of phytoplankton, herbivores and predators, including seals, whales and sea birds.

Despite its undoubted significance, the Antarctic remains a region largely unknown and, until comparatively recently, generally neglected by scientists and the public alike. The first scientific expedition to visit the Antarctic was that of Captain James Cook, who landed at South Georgia on 17th January 1775 and, after a brief inspection, which made plain to him that it was not the hoped for Terra Incognita Australis, consoled himself for not discovering the sixth continent with the thought: 'I must confess the disappointment I now 
met with did not affect me much; for, to judge at the bulk by the sample, it would not be worth the discovery'.

Despite Cook's misgivings the Antarctic was to yield two great harvests from its frigid waters, and we now perhaps see the initial stages of a third. The first harvest was that of the seals, both the valuable fur seal and the lumbering sea elephant, whose blubber was boiled down for oil. Fur seals and sea elephants alike were severely reduced and, the former at least, locally exterminated. Today, however, both species have recovered to form thriving populations.

It was a different story with the whales. The Antarctic whaling industry, begun in December 1904, and stimulated first by demand for whale oil for munitions, and then by the shortage of food fats after two major wars, went on to reduce the population of the larger baleen whales to a mere remnant. No species or race was exterminated, but equally, there is no clearly attested evidence of any stock recovering despite the conservation measures, which in recent years have meant the total prohibition of catching all but the small minke whale. Now only the USSR and Japan catch whales in the Southern Ocean.

But a third generation of harvesting vessels - the stern trawlers - prowl the stormy seas of this inhospitable region. Initially their quarry was fish, but the ecology of the Southern Ocean is such that conventional fin-fish are a less important fraction of the total biomass than in the northern seas. In consequence, the trawlers turned their attentions to what is present in superabundance, the small shrimp-like oceanic krill. Antarctic krillEuphausia superba measures a little over $5 \mathrm{~cm}$ long when full grown and feed directly on the diatoms of the phytoplankton. In turn they are the principal food of the Antarctic baleen whales, the vastly abundant crabeater seals, the Antarctic fur seals, many birds, including the very numerous Adélie and chinstrap penguins, and various fish and squid. Krill form the central link in the Antarctic food web, and in this respect there is a clear contrast with conditions in the north, where not one but many species make up the main food of the principal predators. Krill have the habit of aggregating in swarms (and we know almost nothing of the mechanisms or causes of this process), a feature which makes them available as food to creatures many orders of magnitude larger than themselves, like seals and whales.

Experimental krill fishing began in the early 1960s, about the same time as the fin-fish stocks were being tested, with the USSR as the pioneer. Since that time the fishing has become a serious undertaking with recent total yearly catches topping 100,000 tonnes and perhaps reaching 200,000 tonnes. The USSR and Japan (the nations with whaling interests in the Southern Ocean) are the major krill fishing nations, but Poland has now entered this field and several other states have made small experimental catches while others have expressed interest in what is, at the most conservative estimate, an enormous resource. Although we have very little idea of the real magnitude of the krill resource it is clearly one of the most abundant species on earth. Before the start of commercial whaling, the Antarctic baleen whales were probably eating around 190 million tonnes of krill each year, while the other krill predators would also have accounted for large amounts.

Two recent publications from the International Institute for Environment and Development, Antarctica and its Resources, by Barbara Mitchell and Jon Tinker, and The Management of the Southern Ocean, by Barbara Mitchell and 


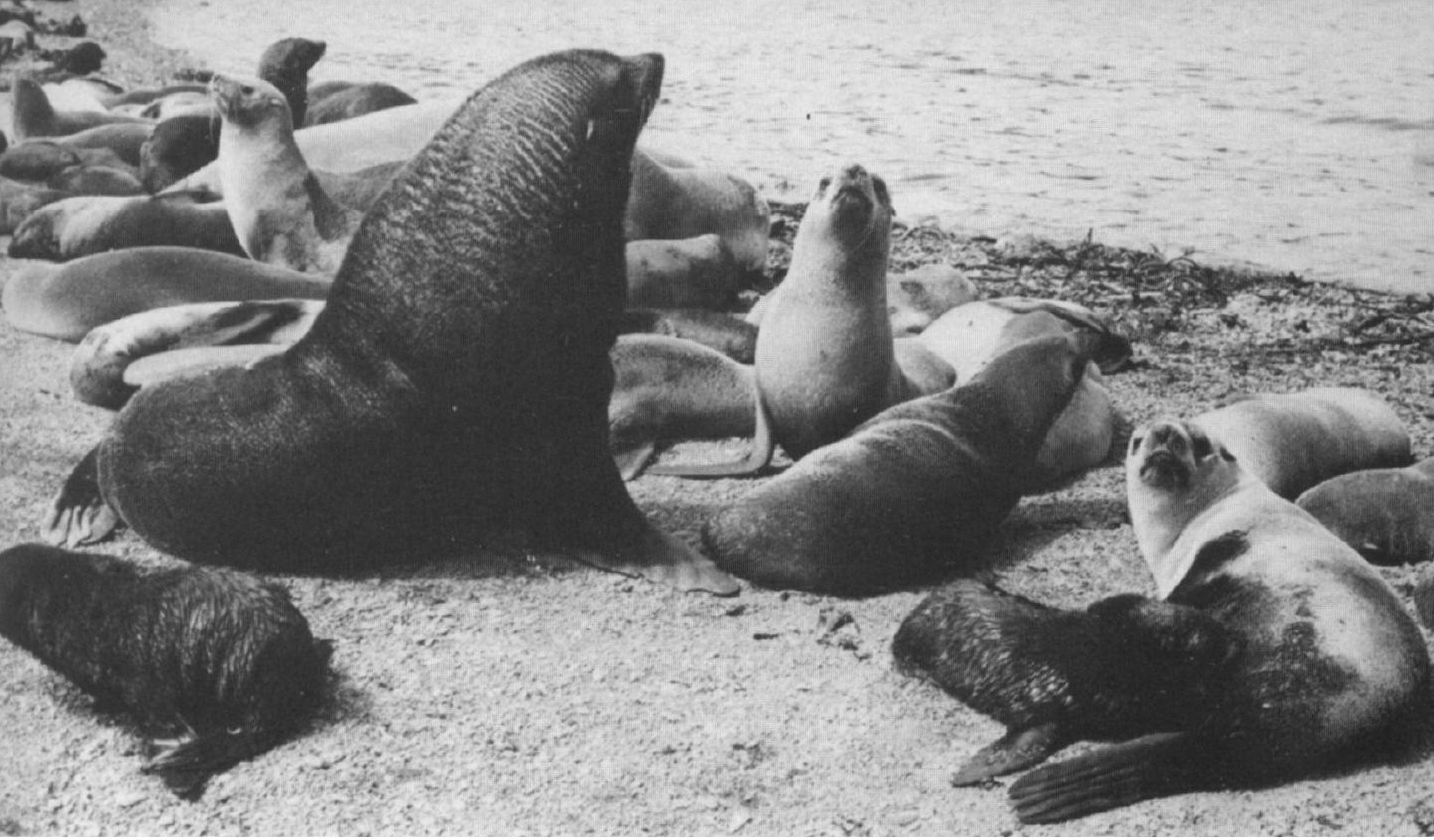

Fur seals on Bird Island, South Georgia

Richard Sandbrook, provide us with a mass of background information on this topic presented in a conveniently accessible form. The first had its origins as a briefing document for journalists at the time of the ninth Antarctic Treaty Consultative Meeting in London in July 1977. It is generally a factual document covering both living and mineral resources, and provides a commentary on the choices ahead.

The second work, which is considerably more extensive, and supported by a reference section, was sponsored by IUCN and WWF and represents a careful consideration of the complex issues of politics, economics and biology involved in a management regime for the Southern Ocean. The authors consider four basic questions:

1. What are the biological resources of the area, and what would be the biological effects of harvesting them?

2. What is the prospect of krill, the main resource, being exploited economically, and how much might be taken and when?

3. Who has an interest in these resources and how can these interests be accommodated?

4. What management structures should be established?

None of these questions allows a simple answer. The first is the simplest, since it involves only matters of fact. It is clear that resources exist in the Southern Ocean in great quantity - though for the most part we cannot expect to quantify them for some time to come - and that krill is the most important of these. We know enough of the complexity of food webs to realise that harvesting one species will have repercussions throughout the food web. In its simplest form we might say that if we harvest krill at its maximum sustainable yield we cannot expect the whale stocks to recover, for their food base will be removed. Similarly if we opt for harvesting a restored stock of whales, as a means of efficient utilisation of the production of the Southern Ocean, we cannot expect simultaneously to maintain a large krill fishery. Current programmes of national and international research, notably the SCAR/SCOR- 
/IABO/ACMRR* programme BIOMASS (Biological Investigations of Marine Antarctic Systems and Stocks) will help to throw light on these questions. The ten-page section on this topic (the preparation of which was assisted by J.R. Beddington and B.T. Grenfell of York University) is a useful introduction, but the reader will need to follow up the references (and a few other unlisted key papers as well) to get a good picture.

The philosophy of maximum sustainable yield exploitation has dominated fisheries management in the past. This involves an attempt to regulate the catch of a particular species in such a way that its future yield is not reduced. But this assumes (among other things) that the stock to be exploited is in a steady state; that the carrying capacity of the environment is constant; and that there exists a density-dependent mechanism in the species exploited, such that reduced numbers in the stock evoke a compensatory rise in rate of recruitment to the breeding stock. These concepts apply best to fish populations (though looking at the state of a good many northern fisheries, one wonders how sound they really are in practice), but it is axiomatic that one cannot apply the MSY concept to both the top and bottom levels of the food chain simultaneously. Nor can we assume that current conditions in the Southern Ocean represent an equilibrium - the enormous perturbation created by the removal of over eighty per cent of the biomass of the baleen whales has created a situation where equilibrium is far off. An ecosystem approach is called for if effective management is to be achieved.

The second question deals with the scale and priming of the possible exploitation of krill. Here the authors are at their strongest, aided on this occasion by Seamus McElroy. Krill is not an ideal resource to harvest; indeed were it not for its swarming habits, it could not be harvested at all, either by man or larger predators. The size of the organism and the very short time it will keep on the deck of a fishing vessel before it begins to spoil make it a troublesome product to process. That it is capable of being processed is proven; machinery has already been produced that peels the shell from krill at a commercial rate. There are no particular problems in locating and catching krill. Ordinary fish finders and commercial mid-water trawl nets fitted with small mesh liners are used; a German fishery research vessel achieved catch rates of about $\mathbf{4 0}$ tonnes per hour with a maximum catch of 30 tonnes in eight minutes!

Krill contains about 15 per cent protein, about the same as butcher's meat or lobster. Three types of products can be produced: tail meats, krill mince and krill meal. Krill meats look and taste like small shrimps and can be used in the same way. Food processors could combine them into larger portions - krill fingers. These would go to a comparatively small market, and would need to be low-priced to compete economically with conventional shrimp. Krill mince (made by squeezing out the meaty part in a filter press and coagulating the result) is similar to the fish mince extensively used in Japan. It can also be used as a delicatessen-type spread, as in the USSR, or made into sausages as in Germany. This too is unlikely to have a large market. Krill meal, to be used as an animal foodstuff, has similar properties to fish meal and here a large market is certainly available. The authors see the success of krill meal as being the

*SCAR: Scientific Committee for Antarctic Research; SCOR: Scientific Committee for Oceanic Research; IABO: International Association of Biological Oceanographers; ACMRR: Advisory Committee on Marine Reserves and Research. 
Nothing in the Treaty was drawn up with resource exploitation in mind, though environmental protection has always been an important element of meetings of the Treaty parties. Terrestrial conservation in the Antarctic depends on the Agreed Measures for the Conservation of Antarctic Fauna and Flora, adopted by the Treaty states in 1964. The Treaty's failure to deal clearly with marine resources made further legislation necessary when the prospect of Antarctic sealing on the high seas was raised. The result was the 1972 Convention for the Conservation of Antarctic Seals, which was signed by the twelve original signatories of the Antarctic Treaty. In the event, commercial sealing did not start again in the Antarctic, but the Convention provides the means of regulating it if it should do so.

The need for more general conservation covering all marine resources, and protecting the ecosystem as a whole, was highlighted by the developments noted earlier. It was the Antarctic Treaty nations that took the initiative on this, and by their effort brought about the Convention on the Conservation of Antarctic Marine Living Resources, signed at Canberra in May 1980.

The negotiations that led up to this were conducted by the Treaty nations in private, in a restricted forum. Barbara Mitchell and Richard Sandbrook cast doubts on the legality of this process. They can find no precedent for a fishery agreement which was negotiated in the absence of some of the existing exploiting nations by a group of states only some of which have (doubtful) sovereignty claims around the region involved, or interests in exploitation. They feel that the interests of the third world in the Southern Ocean (which might be regarded as part of the 'common heritage of mankind') have not been properly considered.

The Treaty group comprises states of widely differing attitudes. Yet they have in common a practical approach, and the Antarctic Treaty itself is good evidence of this. Although in changed circumstances it is perhaps now showing strain, it has clearly worked. Territorial squabbles were shelved and scientific research has gone forward without hindrance. The Treaty approach to the conservation of the Antarctic marine ecosystem was similarly practical and we now have a Convention which provides the necessary legal framework for management. It might have been fairer if the third world and all other members of the UN had been involved in its negotiation, but, bearing in mind the interminable negotiations on the International Law of the Sea, can we believe that we would have reached as satisfactory a stage as we now have? And it is worth observing that no state outside the Treaty has made a significant contribution to Antarctic marine research which might ultimately be of value in controlling exploitation.

The new Convention will be open to accession by any state interested in researching or harvesting in the Southern Ocean, and it is to be hoped that, seeing the advantages of control, those who plan to harvest will accede. I find it hard to understand the authors' hostility to the Treaty. They accuse it of being an exclusive club and the Treaty states of being proprietary towards the resources of the Southern Ocean, views that have been reflected in other conservation-oriented media. Yet if our aim is a legal instrument to provide conservation, the Treaty would seem to have succeeded very well, and, since both international politics and conservation are empirical disciplines, we would do well to assess the benefits of the present arrangement.

This brings us to the fourth question: the management structures needed to 
control exploitation. The principles underlying these are embodied in the text of the new Convention. (Mitchell and Sandbrook give a draft text in an appendix; it differs from the text signed at Canberra principally in the article dealing with the composition of the Commission to be set up.)

The new Convention, unlike the Antarctic Treaty, extends over the whole of the Southern Ocean north to the Antarctic Convergence; it thus covers the biological rather than the political region. Its object is conservation, which includes the concept of rational use, and it aims to ensure that harvesting shall not deplete populations below levels that ensure the greatest net annual increment. The importance of the balance between harvested, dependent and related populations is recognised, and the restoration of depleted populations is one of the objectives. (In parenthesis it may be noted that maintaining populations at levels which produce the greatest net annual increment is not wholly consistent with the restoration of depleted populations; for example, if the blue whale population were to be restored, this would almost certainly involve reduction in the present population of minke whales, crabeater seals and probably other species.) Nevertheless, the application of the 'ecosystem approach' should represent an opportunity for maintaining a balance which will be a great advance on other management practices.

The Convention proposes to achieve these aims by setting up a Commission to facilitate research, collect and analyse data, and adopt conservation measures, including quotas, designated catching areas, protected species or areas, seasons, and regulations for harvesting effort and methods. At the time that Mitchell and Sandbrook wrote, it seemed that membership of this Commission, the controlling body, would be restricted to the Antarctic Treaty states, with acceding states entitled to membership only while researching or harvesting. The Convention as signed, however, added regional economic integration organisations which accede to the Convention. Mitchell and Sandbrook, however, would like to see a wider participation, with other acceding states afforded observer status at the Commission. Decisions are to be taken by consensus, another feature of which the authors disapprove, on the grounds that it tends to favour the exploiters. Yet if general agreement on a decision cannot be reached, experience of the International Whaling Commission has shown there is a real possibility that the dissenters will take advantage of the objection procedure and not be bound by the decision. Common purpose is essential if conservation is to be effective. They are on firmer ground in objecting to the lack of economic regulations and the allocation of national catch quotas: from a conservation point of view, limitation of catch effort (basically the number of vessels employed) on a national basis would probably be the most effective, but it is doubtful if this would have been a realistic objective in the negotiating stages.

I do not find the Convention on Antarctic Marine Living Resources an ideal document, nor do I expect it to operate with total efficiency from the time its Commission is set up. But as a pragmatic conservationist I am grateful that a convention has been formulated and signed which provides the essential framework for conservation and rational exploitation in so important an area. If the nations of the world are determined to make conservation work they can use the Convention for this purpose, and none need suffer because of it.

W. Nigel Bonner, British Antarctic Survey, Natural Environment Research Council, Madingley Road, Cambridge CB3 OET. 